Reprod. Nutr. Dévelop., 1986, 26 (1 B), 275-276.

\title{
Ingestion par le mouton de quelques fourrages méditerranéens d'hiver riches en eau
}

F. GUESSOUS

Institut Agronomique et Vétérinaire Hassan II, BP 6202 Rabat Instituts, Maroc.

Summary. Although the dry matter percentage was low in three forage species harvested during winter in a Mediterranean climate, their intake by sheep was relatively high. This seemed to be related to the low cell-wall content and lignification of these forages and the rapid digestion rate of their dry matter.

II est généralement admis que la forte teneur en eau des fourrages jeunes peut constituer un facteur limitant leur ingestion par les ruminants. Pareille conclusion résulte notamment de la relation positive souvent rapportée entre les quantités ingérées et la teneur en matière sèche (MS) des plantes (Demarquilly, 1966). Elle a été également mise en évidence lors d'essais comparant l'ingestion d'un fourrage vert à celle du même fourrage immédiatement préfané ou deshydraté mais sans autres modifications de ses caractéristiques physico-chimiques (Donefer et Mosi, 1970 ; Verité et Journet, 1970). Les espèces qui poussent en hiver dans les régions irriguées des pays d'Afrique du Nord se caractérisent généralement par une teneur en eau excessivement élevée qui pourrait limiter leur ingestibilité. C'est ce que nous avons étudié chez trois d'entre elles dont la période de production au Maroc s'étale d'octobre à juin : le bersim (Trifolium alexandrinum L.), le trèfle persan (Trifolium resupinatum L.) et le ray-grass italien (Lolium multiflorum L.).

Matériel et méthodes. Pour chacune de ces espèces, les quantités de fourrage vert volontairement ingérées par un lot de six béliers adultes non castrés, nourris à volonté $(10 \%$ de refus), sont mesurées tout au long des différents cycles de croissance de la plante. Un échantillon représentatif du fourrage distribué est analysé chaque semaine pour ses teneurs en matières azotées totales (MAT), parois totales (NDF), lignocellulose (ADF) et lignine au détergent ( $A D L$ ). Parallèlement, la cinétique de digestion in vitro de la matière sèche des feuilles, des tiges et de la plante entière de 18 échantillons de bersim est appréciée par la méthode de Tilley et Terry ; l'incubation dure 6, 24 et $48 \mathrm{~h}$ et elle est suivie d'une digestion pepsique de $48 \mathrm{~h}$.

Résultats et discussion. Pour les trois espèces étudiées, les teneurs moyennes en MS relevées entre octobre et mars oscillent autour de $10 \%$ pour le trèfle persan et le bersim et de $14 \%$ pour le ray-grass italien (tabl. 1). Elles augmentent sensiblement chez les deux dernières espèces lors des cycles reproducteurs d'avril à juin. Les quantités moyennes ingérées pendant la première période sont respectivement 63,69 et $75 \mathrm{~g} \mathrm{MS} / \mathrm{P}^{0,75}$; des niveaux approchant les $90 \mathrm{~g} \mathrm{MS} / \mathrm{P}^{0,75}$ sont quelquefois observés pour le bersim et le ray-grass italien alors que la consommation du trèfle persan reste systématiquement plus faible. Intra-espèces, les corrélations entre les quantités ingérées et la teneur en MS ne sont significatives que pour le bersim et le ray-grass italien $(r=-0,46$ et $-0,47, P<0,05)$. Les teneurs en MAT restent élevées tant que les fourrages sont exploités à un stade végétatif ou feuillu. 
TABL. 1. - Composition chimique et ingestibilité moyennes des fourrages.

\begin{tabular}{|c|c|c|c|c|c|c|c|c|}
\hline \multirow{2}{*}{ Espèce } & \multirow{2}{*}{$\begin{array}{c}\text { Numéro } \\
\text { et nature } \\
\text { des cycles(a) }\end{array}$} & \multirow{2}{*}{$\begin{array}{c}\text { Nombre } \\
\text { de semaines } \\
\text { de mesure }\end{array}$} & \multirow{2}{*}{$\begin{array}{c}\text { Teneur } \\
\text { en MS } \\
\% \\
\%\end{array}$} & \multicolumn{4}{|c|}{ Composition, \% MS } & \multirow{2}{*}{$\begin{array}{l}\text { Quantités } \\
\text { ingérées(b) } \\
g \mathrm{MS} / \mathrm{P}^{0,75}\end{array}$} \\
\hline & & & & MAT & $N D F(c)$ & $A D F(c)$ & $A D L^{(c)}$ & \\
\hline \multirow{2}{*}{ Bersim } & 1 à $4: V$ & 17 & $\begin{array}{c}9,5 \\
(8,4-11,4)\end{array}$ & 19,9 & 29,7 & 23,5 & 3,22 & \multirow{2}{*}{$\begin{array}{c}69 \\
(57-84) \\
58 \\
(47-68)\end{array}$} \\
\hline & 5 et $6 ; \mathrm{R}$ & 9 & $\begin{array}{c}13,5 \\
(9,2-19,1)\end{array}$ & 20,5 & 32,7 & 24,3 & 4,39 & \\
\hline $\begin{array}{l}\text { Trèfle } \\
\text { persan }\end{array}$ & 1 à $3 ; R$ & 8 & $\begin{array}{c}10,0 \\
\{8,5-11,9\}\end{array}$ & 22,5 & 22,6 & 17,6 & 2,06 & $\begin{array}{c}63 \\
(57-71)\end{array}$ \\
\hline \multirow{2}{*}{$\begin{array}{l}\text { Ray-grass } \\
\text { italien }\end{array}$} & 1 à $3 ; F$ & 15 & \multirow{2}{*}{$\begin{array}{c}14,0 \\
(12,3-16,6) \\
15,8 \\
(12,0-22,1)\end{array}$} & 17,5 & 33,1 & 21,3 & 1,14 & \multirow{2}{*}{$\begin{array}{c}75 \\
\langle 65-90\rangle \\
55 \\
(46-64)\end{array}$} \\
\hline & 4 et $5 ; R$ & 12 & & 12,0 & 43,3 & 28,2 & 1,61 & \\
\hline
\end{tabular}

(a) : $V=$ végétatif, $F=$ feuillu, $R=$ reproducteur ; (b) : valeurs extrêmes entre parenthèses ; (c) : valeurs corrigées pour leurs teneurs en matières azotées résiduelles.

Ces niveaux d'ingestion relativement élevés en dépit de la richesse en eau des plantes peuvent être imputés en partie à la faible concentration des constituants pariétaux et à leur degré de lignification réduit, chez ces plantes qui restent longtemps à un stade végétatif et qui poussent sous des températures moyennes ne dépassant pas $14^{\circ} \mathrm{C}$. Les concentrations en NDF observées restent en effet inférieures aux teneurs en constituants pariétaux totaux rapportées dans la littérature pour les espèces des pays tempérés. De même le rapport ADL/NDF reste relativement bas en hiver puisqu'il ne dépasse pas en moyenne $11 \%$ chez les deux trèfles et $4 \%$ chez le ray-grass italien. D'un autre côté, et par rapport à l'ADF et à I'ADL, le NDF est le paramètre le mieux corrélé à l'ingestibilité $(r=-0,50$, $-0,78$ et $-0,83$ respectivement chez le bersim, le trèfle persan et le ray-grass italien).

En utilisant le modèle de Waldo et al. (1972) initialement développé pour décrire la cinétique de digestion des constituants pariétaux des fourrages, on a calculé que la fraction potentiellement digestible de la MS des feuilles, des tiges et de la plante entière de bersim est digérée avec des vitesses moyennes in vitro de respectivement $10,6,9,4$ et $10,3 \%$ par heure. La vitesse de digestion de la plante entière est plus étroitement liée au pourcentage de NDF $(r=-0,51$, $P<0,05)$ qu'aux quantités ingérées $(r=0,12, P>0,05)$.

La concentration et la lignification faibles des parois dans les fourrages méditerranéens d'hiver entraînent une diminution de leur résistance à la réduction en fines particules lors de la mastication et des fermentations dans le rumen. Ceci permet aux animaux de compenser tout au moins partiellement l'effet d'encombrement que l'excès d'eau apportée par ces aliments pourrait avoir sur leur niveau de consommation.

Demarquilly C., 1966. Valeur alimentaire de I'herbe des prairies temporaires aux stades d'exploitation pour le pâturage. II. Quantité ingérée par les vaches laitières. Ann. Zootech., 15, 147-169.

Donefer E., Mosi A. K., 1970. The effect of nitrogen fertilization on the nutritive value of mixed herbage fed fresh and dried. Proc. XI int. Grassland Congr., 717-719.

Verité R., Journet M., 1970. Influence de la teneur en eau et de la deshydratation de l'herbe sur sa valeur alimentaire pour les vaches laitières. Ann. Zootech., 19, 255-268.

Waldo D. R., Smith L. W., Cox E. L., 1972. Model of cellulose disappearance from the rumen. J. Dairy Sci., 55, 125-129. 